\title{
Development of a Relationship between Pavement Condition Index and International Roughness Index in Rural Road Network
}

\author{
Sasan Adeli $\mathbb{D}^{1},{ }^{1}$ Vahid Najafi moghaddam Gilani $\mathbb{D}^{2},{ }^{2}$ Mohammad Kashani Novin $\mathbb{D}{ }^{2}$ \\ Ehsan Motesharei $(\mathbb{D})^{3}$ and Reza Salehfard $\mathbb{D D}^{2}$ \\ ${ }^{1}$ Department of Civil Engineering, Imam Khomeini International University, Qazvin, Iran \\ ${ }^{2}$ School of Civil Engineering, Iran University of Science and Technology, Tehran, Iran \\ ${ }^{3}$ School of Civil Engineering, K. N. Toosi University of Technology, Tehran, Iran
}

Correspondence should be addressed to Reza Salehfard; rsalehfard@yahoo.com

Received 23 October 2020; Revised 26 April 2021; Accepted 14 August 2021; Published 21 August 2021

Academic Editor: Valeria Vignali

Copyright (c) 2021 Sasan Adeli et al. This is an open access article distributed under the Creative Commons Attribution License, which permits unrestricted use, distribution, and reproduction in any medium, provided the original work is properly cited.

The main objective of this paper was to investigate the relationship between PCI and IRI values of the rural road network. To this end, 6000 pavement sections of the rural road network in Iran were selected. Road surface images and roughness linear profiles were collected using an automated car to calculate PCI and IRI, respectively. Three exponential regression models were developed and validated in three different IRI intervals. Analysis of the results indicated that exponential regression was the best model to relate IRI and PCI. In these models, $R^{2}$ values were found to be acceptable, equal to $0.75,0.76$, and 0.59 for roads with good, fair, and very poor qualities, respectively, indicating a good relationship between IRI and PCI. Moreover, validation results showed that the model had a high accuracy. Also, the relation between IRI and PCI became weaker as a result of increasing the level of road surface roughness, which can be caused by the increase in the number and severity of failures. Furthermore, two failures of rail R.C. and rutting were rarely observed in the studied roads. Therefore, the proposed model is more applicable for roads without the mentioned failures and asphalt-pavement rural road network.

\section{Introduction}

Managing the highway infrastructure leads to increasing traffic safety and reducing the future probable costs of pavements renovating [1]. On the other hand, road agencies must evaluate the efficiency and cost-effectiveness of maintaining a road network at the required performance levels over the service life, based on which decisions are made and pavement management analysis is conducted. Therefore, pavement quality evaluation and surface failure characteristics are significant factors in the design and lifecycle time.

Pavement failures can be classified into two types: functional failures and structural failures, and also, the inspection methods used to verify damage type can be categorized into four conditions: structural, surface distress, safety or skid, and roughness. Structural conditions are related to structural failure, but others are associated with functional failure. Therefore, there are various indices to determine the quality of asphalt pavement, the most important of which are pavement condition index (PCI), present serviceability index (PSI), and present serviceability rating (PSR). PCI is the custom index for evaluating pavement quality and is a numerical index regarding structural and functional surface distress based on a specified guideline, ranging from 0 for a failed pavement to 100 for pavement in perfect condition [2].

Some studies have utilized PCI in maintenance and rehabilitation planning [3-5]. Also, according to the definition of the American Society for Testing and Materials [6], roughness is the deviation of a surface from a planar surface with characteristic dimension and ride quality. Besides, the international roughness index (IRI) is employed to evaluate the roughness of pavements. It can also be used for summarizing roughness qualities that affect vehicle response. Road surface roughness is an important parameter that 
indicates the comfort level of the ride over a road surface and is also related to safety, vehicle vibration, operating speed, vehicle operating cost, etc. [2]. That is why IRI has become a prominent index in Pavement Management System (PMS), especially to calculate vehicle operating cost in many countries [7]. Also, models of prediction based on IRI are used in studies as pavement deterioration and pavement condition improvement models [8-11].

In developing countries, and especially in Iran, the data for asphalt concrete failure (PCI) and IRI are not available on most of the roads due to limited budget and equipment [12]. For instance, there are few data collection tools, especially for IRI. Hence, decision-makers prefer to utilize this equipment for roads that have higher traffic volumes such as freeways and highways. Therefore, in this study, the relationship between pavement condition index and international roughness index in rural road network will be examined.

1.1. Literature Review. There have been numerous studies relating asphalt concrete pavement quality indices and surface roughness, such as Al-Omari and Drater [13] on relating IRI and PSR, Sharaf and Fathi [14] on associating IRI and PCI, and Hall and Muñoz [15] on relating IRI and PSI.

Some researchers developed regression models to relate pavement failures and IRI. In the WesTrack Project, Mactutis et al. [16] presented a relationship between IRI and pavement failures. In this relationship, IRI $(\mathrm{m} / \mathrm{km})$ depended on initial IRI, fatigue cracks (alligator and longitudinal cracks), and rutting depth $(\mathrm{mm})$, while other pavement failures were not considered. IRI values ranged between 0.825 and 3.454 , the majority of which were between 0.825 and 1.7 . The relationship demonstrated the dependency of IRI on the initial value of IRI and sensitivity to the surface of fatigue cracks, while it was not sensitive to rutting depth.

Another linear regression model was developed by Dewan and Smith [17] to estimate IRI using PCI in San Francisco Bay Area roads. The failures included alligator cracking, block cracking, longitudinal and transverse cracking, depression and rutting, patching and utility cut patch, distortion, and weathering and raveling cracks. The severity of cracks was classified as low, medium, and high. The majority of measured IRIs were less than 3 . In this study, the relationship between PCI and IRI and different failures with different severities were evaluated. Only the linear regression model between IRI and PCI was statistically and logically acceptable. The regression relationship was

$$
\mathrm{IRI}=0.0171(153-\mathrm{PCI})\left(R^{2}=0.53\right),
$$

where IRI is in $\mathrm{m} / \mathrm{km}$. The $R^{2}$ value of the model was 0.53 with a coefficient of variation of $28 \%$. The observed and predicted values of IRI were compared for model validation.

Park et al. [18] found a power relationship between PCI and IRI using the data on North American roads. Pavement profile PCI was calculated using micropaver. The model predicted PCI values based on small IRIs between 0.725 and 2. Caution should be exercised in using the model outside the recommended IRI range. As future work, this study suggested the use of a wider interval of IRI for model development. The relation was as follows:

$$
\log \mathrm{PCI}=\log 87.098-0.481 \mathrm{IRI}\left(R^{2}=0.66\right),
$$

where IRI is in $\mathrm{m} / \mathrm{km}$.

Sandra and Sarkar [19] established a linear regression model to estimate IRI based on the severity and area of five major failures in Indian roads. The $R^{2}$ value of the model was 0.986. The five failures included cracking, potholes, rutting, raveling, and patching. Results indicated that potholes and raveling have the most impact on the model on Indian roads.

Similar to Sandra and Sarkar [19] and considering cracking, potholes, patching, rutting, raveling alligator cracking, and edge failure, Prasad et al. [20] presented a regression model to calculate IRI for Pradhan Mantri Gram Sadak Yojana (PMGSY) roads in which $R^{2}=0.66$. In this study, alligator cracking failures with high severity and potholes with a medium severity had the highest coefficients which mean that these two failures have a high impact on IRI.

Arhin and Noel [21] developed exponential regression models to predict PCI from IRI values. According to the performance class and types of pavement, these models were classified into two general sections: one was based on road performance class, freeway, arterial, collector, and local, while the other was based on types of pavement, asphalt concrete, concrete, and composite. Seven regression equations were presented based on this classification. The results revealed that according to the very small values of $R^{2}$, the models may only explain a low percentage of variations in data and, thus, cannot predict the results accurately enough.

In addition, there are studies using modern techniques such as neural networks and genetic programming (GP). Lin et al. [22] achieved a relation between IRI and 10 types of common pavement failure in Taiwan via feed-forward neural network backpropagation. The failures included rutting, alligator cracking, cracking, patching, potholes, corrugation, manholes, stripping, and bleeding. Some of the failures proved more important in the calculation of PCI.

Shahnazari et al. [23] estimated PCI using GP, ANN, and pavement failures. The models were developed mostly by the data in the range of 80-100. In comparison with fieldmeasured values, the values estimated in both GP and ANN approaches had an acceptable error. However, the ANN technique was more precise than GP. Regarding the data focus on a PCI of more than 60, there were more errors in the estimation of items with a PCI of less than 40 .

Arabani et al. [24] proved the stronger performance of the rough set theory for solving road pavement management problems in comparison with the other applied methods. The amount of data needed for modelling the problem would be decreased using rough set theory method.

Elhadidy et al. [25] presented models to determine the relationship between PCI and IRI. They found the best relationship between PCI and IRI with a coefficient of determination $\left(R^{2}\right)$ of 0.995 . The bias in the predicted IRI values was significantly very low. The model validation using a different dataset also yielded highly accurate predictions $\left(R^{2}=0.992\right)$. 
Piryonesi and El-Diraby [26] showed that the correlation between the IRI and the PCI was stronger in the Long-Term Pavement Performance (LTPP) database. They investigated the variations not explained by regression models, i.e., reasons that road sections could have an excellent PCI and poor IRI and vice versa. Besides, the relationship between the PCI and IRI can vary significantly based on factors such as location, functional class, and slope.

Bashar and Torres-Machi [27] presented three metaheuristic algorithms commonly used to predict international roughness index (IRI) and compared their performance to traditional techniques. They indicated that machine learning algorithms capture on average $15.6 \%$ more variability than traditional techniques. Random forest was the most accurate technique with an overall performance value of 0.995 . ANN was also identified as a highly effective technique that has been widely used and provides accurate predictions with both small and large sample sizes.

According to reviewed references, the relations are used for IRI values which are less than 3 and small IRI ranges. Also, all the models are based on limited database information. In most of the studies, there are only a few failures related to IRI. In general, it can be observed that the relation between IRI and pavement failures is reasonable, and the effective method to estimate IRI differs based on different regions and roads. Furthermore, all of the relations are local and cannot be utilized for other regions, and models are required to be calibrated by regions and road conditions.

1.2. Purpose of Study. The main objective of this paper was to investigate the relationship between PCI and IRI and present a model which estimates PCI based on IRI values and vice versa. In order to achieve this aim, 6000 pavement sections from $600 \mathrm{~km}$ of rural road network in Fars Province were selected as study sites. For measuring PCI and IRI of roads, a van vehicle "Tadbirgare Rah" was used which collects surface failures and longitude roughness profile to calculate PCI and IRI, respectively. Also, the most distinctive novelty of this paper is a new domestic automated car that was used to determine the PCI information in rural areas. Eventually, log-linear regression model was developed and validated.

\section{Data Collection}

Field data were collected using "Tadbirgare Rah." Tadbirgare Rah is a van vehicle in which the advanced evaluation equipment for road evaluation is implemented. This machine collects road and airport network data including surface failures, roughness, pavement drainage conditions, and road safety in the shortest time. Tadbirgare Rah is illustrated in Figure 1.

In order to obtain PCI, the images of the road surface were taken on the studied roads. Following the image analysis, a continuous roll from the road surface was obtained, as shown in Figure 2.

The images were imported in the Road Mapper software using which the area or length, type, and severity of failures were specified in the next step. In this study, the failures

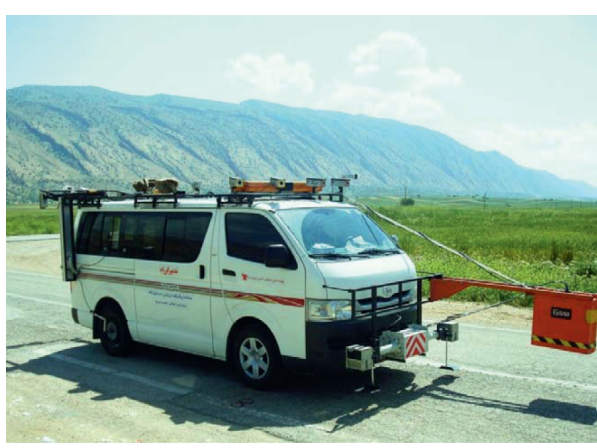

Figure 1: “Tadbirgare Rah” automated car.

which were used to calculate PCI included alligator cracking, longitudinal cracking, transverse cracking, block cracking, rutting, edge failure, corrugation, weathering and raveling, joint reflection, patching, potholes, polished aggregates, slippage, and rail-road crossing (rail R.C.). In this figure, alligator, transverse, and longitudinal cracking are predominant distress types.

PCI calculation in Road Mapper based on the ASTM D6433 [28] standard is demonstrated in Figure 3. Detection of distress type, determination of distress severity, and calculation of distress area or length were conducted in the Road Mapper software.

The design and construction of this machine for collecting road longitude profiles are based on the ASTM-E950 [29] standard and Global Bank certificates. IRI was obtained based on the longitude roughness profile using the Road Analyser software.

To collect data, $600 \mathrm{~km}$ of roads in Fars Province, Iran, were considered. The chosen roads were paved with asphalt concrete with two or multiple lanes. PCI and IRI values were calculated in $100 \mathrm{~m}$ longitude and $1 \mathrm{~m}$ width sections continuously along the road. There a total of 6000 pavement sections were prepared.

In this study, rail R.C. failure did not exist in the selected roads. Rutting was observed in few profiles and was negligible. The frequencies of PCI values are shown in Figure 4(a). Most of the cases were in the range of 80 to 100 . At the same time, the frequencies of IRI values are depicted in Figure $4(\mathrm{~b})$ where $0<\mathrm{IRI}<3.5$ were the predominant frequencies.

\section{Model Development}

Model development can be affected by outlying or erroneous data. Therefore, 510 sections were identified and omitted as results of tarnished images, visual errors, image quality, and geographical coordinate errors. According to model development, a constant relation was found between IRI $<2.5$ and PCI. It means that PCI values of 1867 sections with IRI values of less than 2.5 were equal to 100 . Therefore, no regression model development was required. A total of 2537 out of 3623 remaining sections ( $70 \%$ of sections) were selected randomly and used for model development. The data on 1086 sections ( $30 \%$ of the observed values) were reserved model validation. 


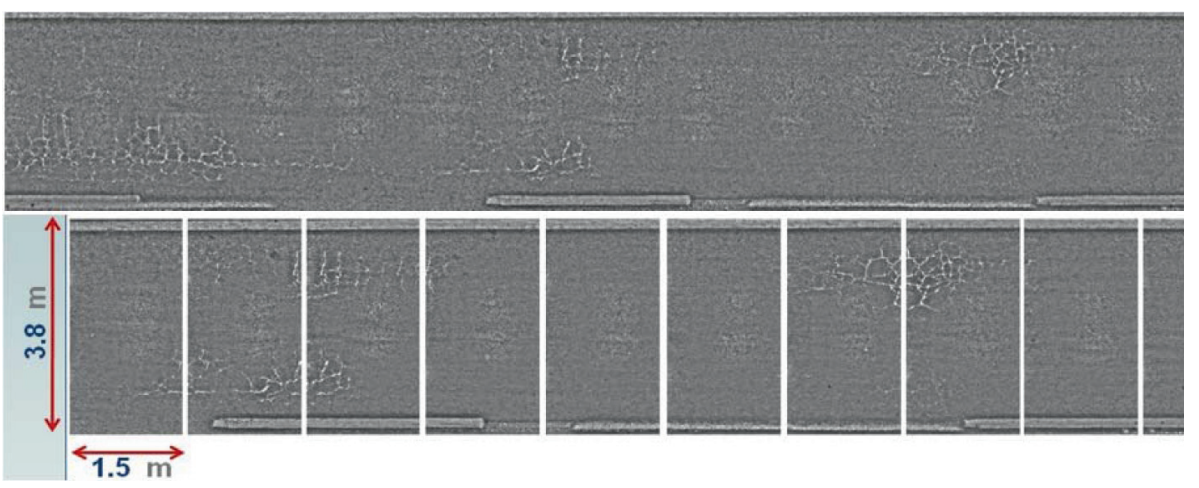

FIgURE 2: Continuous roll from road surface.

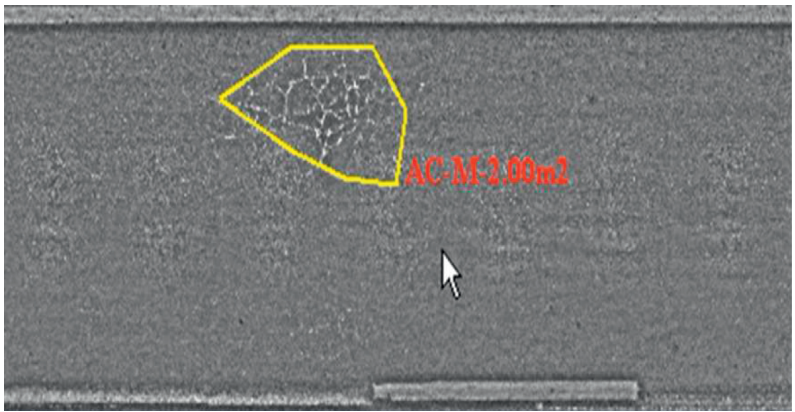

Figure 3: A sample of PCI calculation in Road Mapper software.

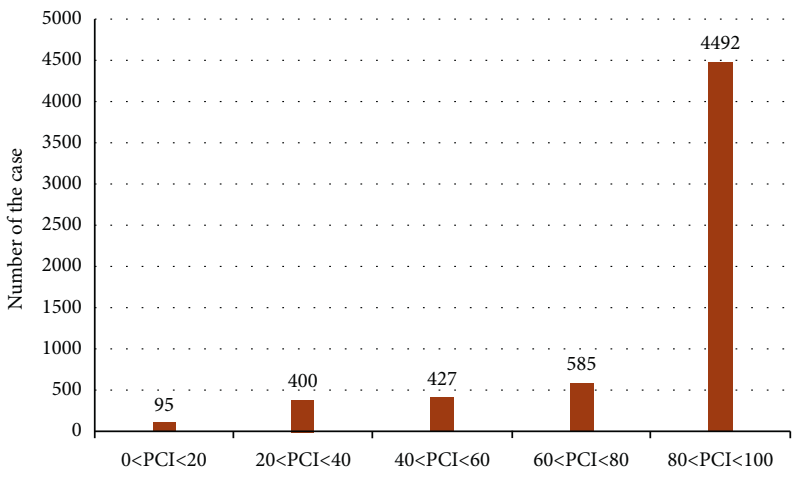

(a)

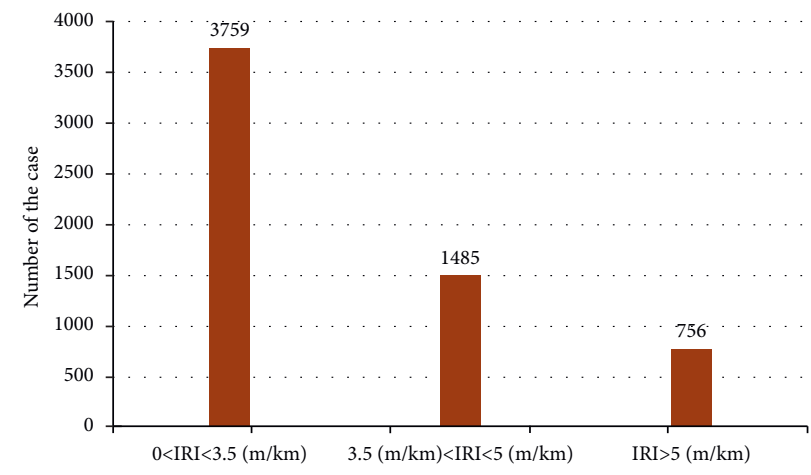

(b)

FIgURE 4: Frequencies of the cases versus (a) PCI ranges and (b) IRI ranges.

IRI and PCI are two pavement quality indices that are inversely related, i.e., as the pavement deteriorates, PCI decreases, and IRI increases. Regarding the relationship between IRI and PCI values in different qualities of pavement, the variation rate of PCI is different from that of IRI. In a small range of IRI, the difference in variation rate is small, but this rate becomes larger by increasing pavement quality and PCI.

Initially, model development was performed for all the ranges of IRI in one model, while separated models for such large-ranged data increase the accuracy. Also, the variation rate of PCI values is different in the range of IRI values. Thus, IRI was divided into three ranges according to Washington Department of Transportation instructions based on road pavement quality to relate PCI and IRI. The mean, maximum, minimum, and standard deviation (Std. D.) values of these data were calculated and are given in Table 1. To determine the normality of PCI data, the Kolmogorov-Smirnov test was performed and the result is shown in Table 2. The result shows that the significance level in the K-S test (represented by sig.) was more than 0.05 , meaning that the null hypothesis $\left(H_{0}\right)$ failed to be rejected, which is the natural distribution of the variables. So, the distribution was normal and parametric tests were used.

To investigate the relationship between IRI and PCI, different functions such as linear, power, and exponential were examined. Among them, the exponential model was selected as the most appropriate. The log-linear regression is 
TABLe 1: Kolmogorov-Smirnov test results for PCI normal distribution.

\begin{tabular}{lccr}
\hline \multirow{2}{*}{ IRI range } & \multirow{2}{*}{ Observed parameter } & \multicolumn{2}{c}{ Kolmogorov-Smirnov } \\
& & Statistic & df \\
\hline $2.5-3.5$ & PCI & 0.098 & 2548 \\
$3.5-5$ & PCI & 0.069 & 545 \\
$5-8$ & PCI & 0.057 & 480 \\
\hline
\end{tabular}

TABLE 2: Range of international roughness index and pavement condition index and associated parameters.

\begin{tabular}{|c|c|c|c|c|c|c|c|}
\hline IRI range & Observed parameter & Number of sections & Unit & Mean & Min. & Max. & Std. D. \\
\hline \multirow{2}{*}{$2.5-3.5$} & PCI & 2598 & - & 97.51 & 86.49 & 99.48 & 3.21 \\
\hline & IRI & 2598 & $\mathrm{~m} / \mathrm{km}$ & 2.97 & 2.53 & 3.47 & 0.26 \\
\hline \multirow{2}{*}{$3.5-5$} & PCI & 545 & - & 68.31 & 44.25 & 89.48 & 16.04 \\
\hline & IRI & 545 & $\mathrm{~m} / \mathrm{km}$ & 4.14 & 3.51 & 5.00 & 0.46 \\
\hline \multirow{2}{*}{$5-8$} & PCI & 480 & - & 36.75 & 4.14 & 51.34 & 22.37 \\
\hline & IRI & 480 & $\mathrm{~m} / \mathrm{km}$ & 5.82 & 5.00 & 8.01 & 1.16 \\
\hline
\end{tabular}

based on the premise that the natural logarithm of $Y_{i}$ has a normal distribution with the mean of $\mu \mathrm{i}$ and the variance of $\sigma^{2}$. It also ensures that $Y_{i}$ should expect to remain positive. In this model, the relationship between the expected $Y_{i}$ and $X_{i}$ predictor variables is expressed as follows [30]:

$$
\ln \left(Y_{i}\right)=\beta_{o}+\beta_{1} X_{i 1}+\cdots+\beta_{q} X_{i q}
$$

where $Y_{i}$ is the dependent variable, $X_{i}$ 's are independent variables, and $\beta_{i}$ are calibrating coefficients of the regression. The model was developed via the SPSS program.

According to Washington Department of Transportation instructions, IRI $<2.5$ is classified as very goodquality roads. Model development was performed for other ranges with good-quality roads $(2.5<\mathrm{IRI}<3.5)$, fair-quality roads $(3.5<\operatorname{IRI}<5)$, and poor-quality roads $(5<\mathrm{IRI}<8)$. Exponential regression analysis was performed between IRI as the independent variable and PCI as the dependent variable. Based on $R^{2}$ values, there was a very good relationship between PCI and IRI. However, PCI was over 100 in a very small range of IRI. The relations are as follows:

$$
\begin{aligned}
\mathrm{PCI} & =4.915-0.1126 \mathrm{IRI} \text { for } 2.5<\mathrm{IRI}<3.5, \\
R^{2} & =0.75, \\
R_{\mathrm{adj}}^{2} & =0.74, \\
\mathrm{PCI} & =6.038-0.438 \mathrm{IRI} \text { for } 3.5<\mathrm{IRI}<5, \\
R^{2} & =0.76, \\
R_{\mathrm{adj}}^{2} & =0.75, \\
\mathrm{PCI} & =5.54-0.332 \mathrm{IRI} \text { for } 5<\mathrm{IRI}<8, \\
R^{2} & =0.59, \\
R_{\mathrm{adj}}^{2} & =0.58,
\end{aligned}
$$

in which IRI $(\mathrm{m} / \mathrm{km})$ is the international roughness index and PCI is the pavement condition index. In this model, all $R^{2}$ values are more than 0.59 and the adjusted $R_{\text {adj }}^{2}$ values are more than 0.58 , demonstrating a good relationship between
IRI and PCI. The F value of the model in the ANOVA table is acceptable, and the assumption of the linearity of the relation between IRI and LnPCI is valid. In addition, the significant $P$ value for this model is high $(P<0.0001)$. Table 3 lists the statistical information for three equations.

\section{Model Validation}

It has already been mentioned that $30 \%$ of the randomly selected data points were kept aside for the validation of the model. Furthermore, the predicted and observed values of PCI were statistically compared, and absolute percentage deviations (APDs) were calculated for each stretch using equation (5) to determine the robustness of the model.

$$
\mathrm{APD}=\frac{[\text { Observed }(\mathrm{PCI})-\text { Predicted }(\mathrm{PCI})]}{\text { Observed }(\mathrm{PCI})} \times 100
$$

Using the APD of all the stretches, the mean absolute percentage deviation (MAPD) between the observed PCI and the predicted PCI was calculated. The absolute percentage of deviation was very high in most cases. MAPD was found to be $5.3 \%, 4.7 \%$, and $10.1 \%$ for equations $(4 a)-(4 c)$, respectively, which is acceptable.

However, in a few cases, the deviations were high. The variations in the observed and calculated values in a few isolated cases may be attributed to various reasons including the fact that some of the parameters used for calculating PCI were not considered in calculating IRI. To validate the model, a plot was also drawn for the predicted pavement condition values as ordinates and the observed pavement condition as abscissa, as shown in Figure 5. A $45^{\circ}$ line was drawn to see the distribution of plotted points on either side of the ideal line. Based on Figure 5, it can be observed that the majority of the points are close to the line.

Table 4 presents a summary of the $t$-test results which compared the average observed $\mathrm{PCI}\left(\mathrm{PCI}_{\mathrm{O}}\right)$ with the average predicted PCI $\left(\mathrm{PCI}_{\mathrm{P}}\right)$. The significance is more than 0.05 . Therefore, it can be deduced that the averages of the predicted and observed PCI do not have a significant difference. 
TABLE 3: ANOVA for regression and parameter estimates with one predictor variable.

\begin{tabular}{|c|c|c|c|c|c|c|c|c|}
\hline & Model & Sum of squares & df & Mean square & $F$ & $P$ value & $R-\mathrm{Sq}$ & Adj $R-S q$ \\
\hline \multirow{3}{*}{ a } & Regression & 1.546 & 1 & 1.546 & 5341.007 & 0.0001 & 0.75 & 0.74 \\
\hline & Residual & .526 & 1817 & 0.000 & & & & \\
\hline & Total & 2.072 & 1818 & & & & & \\
\hline \multirow{3}{*}{$\mathrm{b}$} & Regression & 15.225 & 1 & 15.225 & 1195.996 & 0.0001 & 0.76 & 0.75 \\
\hline & Residual & 4.837 & 380 & 0.013 & & & & \\
\hline & Total & 20.062 & 381 & & & & & \\
\hline \multirow{3}{*}{ c } & Regression & 49.485 & 1 & 49.485 & 478.941 & 0.0001 & 0.59 & 0.58 \\
\hline & Residual & 34.510 & 334 & 0.103 & & & & \\
\hline & Total & 83.995 & 335 & & & & & \\
\hline
\end{tabular}

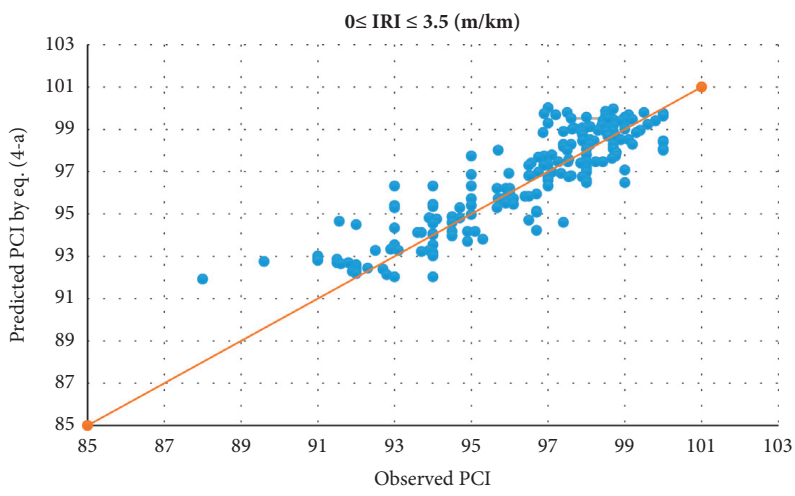

(a)

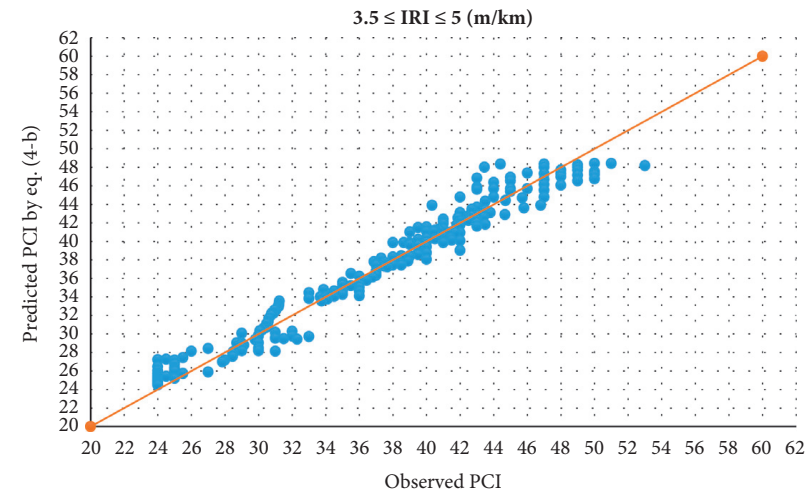

(b)

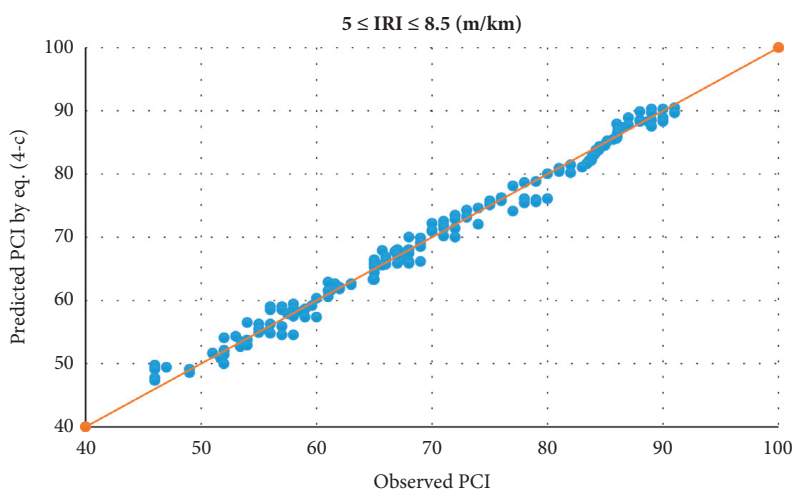

(c)

FIgURE 5: (a) Plot between predicted and measured PCI due to IRI, equation (4a). (b) Plot between predicted and measured PCI due to IRI, equation (4b). (c) Plot between predicted and measured PCI due to IRI, equation (4c).

TABLE 4: T-test results for predicted and observed pavement condition index.

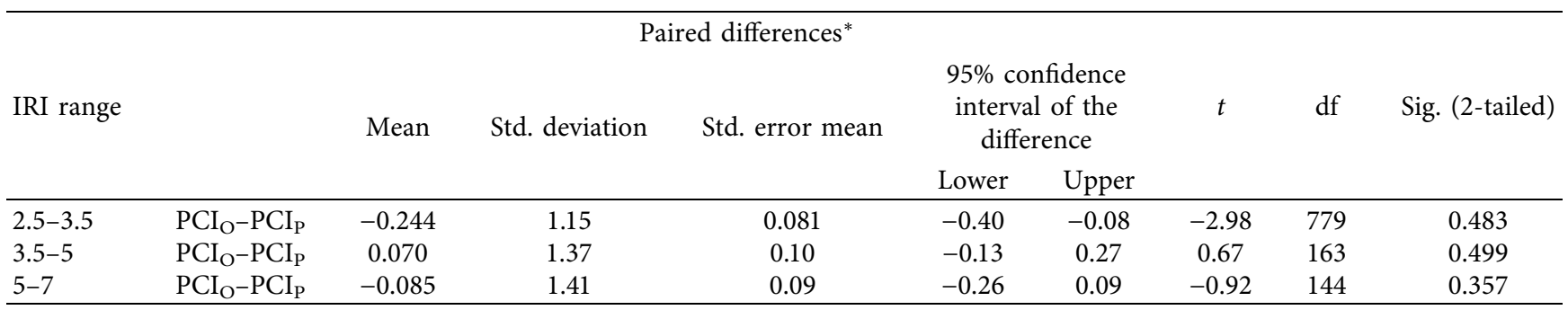

${ }^{*} \mathrm{PCI}_{\mathrm{O}}$, observed pavement condition index; $\mathrm{PCI}_{\mathrm{P}}$, predicted pavement condition index. 


\section{Analysis of Results}

As mentioned in model development, the relationship between IRI and PCI was classified into 3 classes. In some ranges, there was a strong relationship between the two variables that were selected to develop the model. In the presented model, PCI was approximately 100 in IRI $=2.5$ (equation (4a)). It was 91.9 and 90.5 in $\mathrm{IRI}=3.5$, using equations (4a). and (4b), respectively. Therefore, in $2.5<$ IRI $<3.5$, road quality was excellent based on the ASTM D6433 [20] standard and has the least surface failures. PCI varied between 90 and 47 in $3.5<\mathrm{IRI}<5$, i.e., the pavement condition was very good, good, and fair. PCI variation was between 47 and 25, i.e., fair and poor conditions in $5<\mathrm{IRI}<8$.

According to $R^{2}$ and validation results, the accuracy of equation (4c) was less than the other equations. It can be seen that as road surface distresses increased, the relation between IRI and PCI weakened, probably caused by the increase in failures which have a low impact on roughness as well as the increased effectiveness of parameters that are not considered in model development.

In some ranges, there was no acceptable relation between PCI and IRI. In the collected data in this study, the majority of corresponding PCIs with IRI $<2.5$ were 100 . Hence, it was not necessary to develop a model in $1<\mathrm{IRI}<2.5$.

In addition, placing IRI $=7$ in equation (5), PCI was approximately 25 . Therefore, roads with IRI $>7$ had a $\mathrm{PCI}<25$ which is a weak condition, and the relationship between IRI and PCI was not reasonable because pavement profiles require major rehabilitation activities or reconstruction. Figure 6 illustrates the overall range of the model IRI values and the predicted PCI based on Shahin's PCI classification [2].

Equations (4a)-(4c) and other reviewed equations were compared and are graphically shown in Figure 7. In each model, PCIs were different in the same IRI. For example, when IRI $=2.5, \mathrm{PCI}$ is 7,56 , and 100 in study by Dewan and Smith [17] (equation (1)), study by Park et al. [18] (equation (2)), and the present model (equations (4a)-(4c)), respectively. The $R^{2}$ values of various models have been shown according to Figure 7 . The significant point is that most of the models are logarithmic and the difference between the models of the present study with other researchers is in the different range of obtained IRI. These values have a considerable difference. Probable reasons for the difference in the diagrams are listed as follows:

(1) Different road type classification: in two other studies, long-term pavement performance (LTPP) data which belong to highways and freeways were utilized, while in this study, data were collected from multiple-lane rural roads.

(2) The difference in road construction quality in different countries: construction quality is based on equipment, materials, machinery, and construction standards such as acceptation limit for minimum quality of newly constructed roads.

(3) Failure type of pavement in every region can be another reason for this issue. for instance, failures

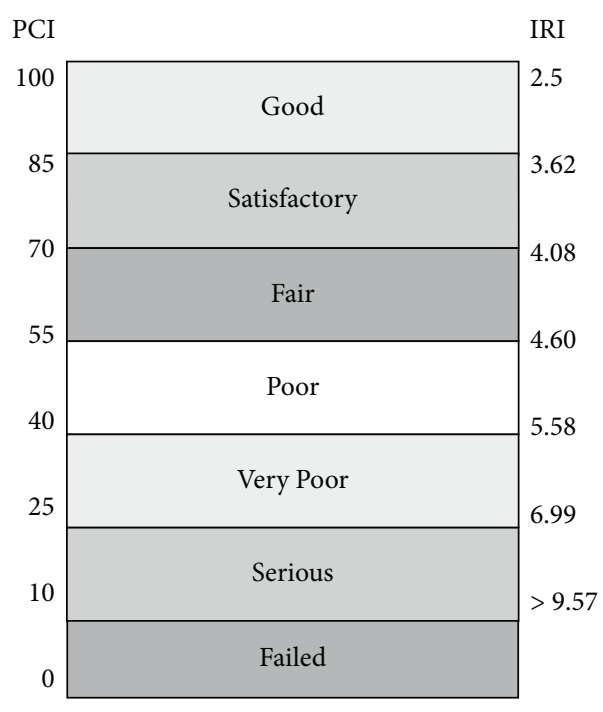

FIGURE 6: Pavement quality for given IRI and PCI values based on Shahin's PCI classification [2].

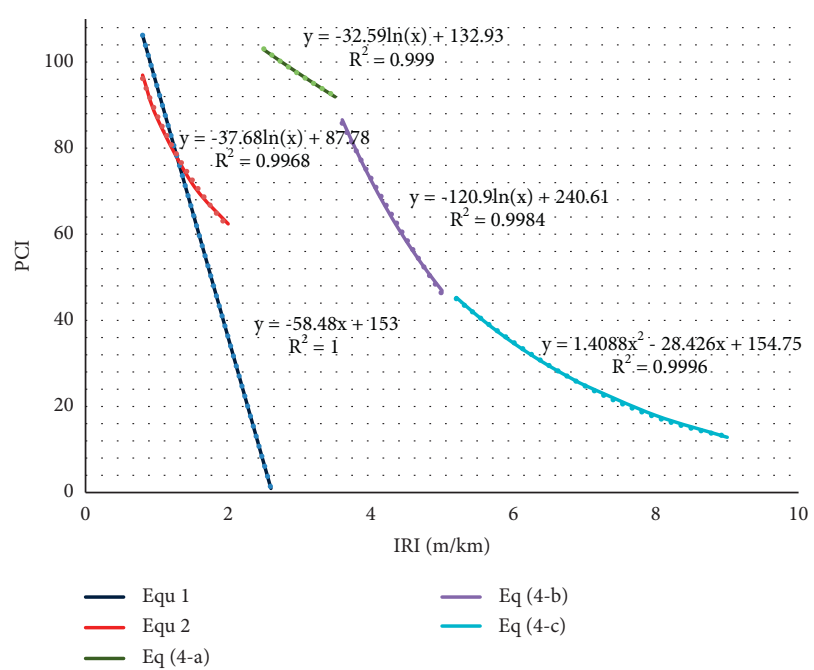

Figure 7: Comparison of equations (4a)-(4c) curve and equations (1) and (2).

including bleeding, weathering, and even alligator cracking with a low severity can affect PCI calculation, while they have a very low impact on longitude profile roughness.

(4) In addition, as mentioned in the literature review, the ranges of IRIs are very limited in two other studies, and further analysis is required for wider ranges of IRI.

\section{Conclusions}

In order to facilitate decision-making in road pavement maintenance and rehabilitation and cost reduction, the present study was conducted to develop a relationship between two of the most important pavement quality evaluation indices, IRI and PCI. The model was based on field database information collected from 6000 pavement sections of $600 \mathrm{~km}$ of rural road network in Fars Province, 
Iran. PCI considering 15 different types of pavement failure and IRI were calculated as can be seen in the Data Collection section. The database included a wide range of IRI from 1 to 8 . Therefore, three different ranges were established based on IRI values and a unique relationship was achieved for each interval. The major findings of this research are as follows:

(1) The exponential regression model had the highest correlation and the least error in comparison with linear and logarithm models for the selected ACpavement rural roads. Therefore, exponential regression is the best model to relate IRI and PCI.

(2) Based on the results, $R^{2}$ values were found to be acceptable, equal to $0.75,0.76$, and 0.59 for roads with good, fair, and very poor qualities, respectively. The obtained equations developed a good relationship between IRI and PCI. Furthermore, validation results showed that the model has a high accuracy.

(3) According to $R^{2}$ and validation results when the level of road surface roughness increases, the relation between IRI and PCI becomes weaker, which can be caused by the increase in the number and severity of failures.

(4) In the studied roads, two failures of rail R.C. and rutting were rarely observed. Therefore, the proposed model is more useful for roads without the mentioned failures and asphalt-pavement rural road network.

(5) The developed model is practically applicable. However, applying this relation is recommended in local roads. It must be applied to others with caution because of different construction, road classification, and climatic conditions.

(6) We suggest that more variables other than IRI be employed for predicting PCI in the future. Furthermore, similar relationships can be obtained for different classification roads. Also, other machine learning techniques can be provided to be incorporated into the proposed approaches to obtain more accurate results [31-33].

\section{Data Availability}

The data used to support the findings of this study are available from the corresponding author upon request.

\section{Disclosure}

This research did not receive any specific grant from funding agencies in the public, commercial, or not-forprofit sectors.

\section{Conflicts of Interest}

The authors declare that they have no conflicts of interest or personal relationships that could have appeared to influence the work reported in this paper.

\section{References}

[1] B. Zarei and G. A. Shafabakhsh, "Dynamic analysis of composite pavement using finite element method and prediction of fatigue life," Computational Research Progress in Applied Science and Engineering, vol. 4, no. 2, 2018.

[2] M. Y. Shahin, Pavement Management for Airports, Roads and Parking Lots, Springer, New York, NY, USA, 2nd edition, 2005.

[3] K. A. Abaza, S. A. Ashur, and I. A. Al-Khatib, "Integrated pavement management system with a markovian prediction model," Journal of Transportation Engineering, vol. 130, no. 1, pp. 24-33, 2004.

[4] H. Sahin, P. Narciso, and N. Hariharan, "Developing a fiveyear maintenance and rehabilitation $(M \& R)$ plan for HMA and concrete pavement networks," in proceedings of the 2nd International Conference on Civil Engineering, Stockholm, Sweden, September 2014.

[5] C. U. Chikezie, A. T. Olowosulu, and O. S. Abejide, "Multiobjective optimization for pavement maintenance and rehabilitation programming using genetic algorithms," Archives of Applied Science Research, vol. 5, no. 4, pp. 76-83, 2013.

[6] ASTM E867-06, Standard Terminology Relating to VehiclePavement Systems, ASTM international, West Conshohocken, PA, USA, 2012.

[7] X. Zhang and H. Gao, "Road maintenance optimization through a discrete-time semi-Markov decision process," $R e$ liability Engineering \& System Safety, vol. 103, pp. 110-119, 2012.

[8] S. Labi and K. C. Sinha, "Life-cycle evaluation of flexible pavement preventive maintenance," Journal of Transportation Engineering, vol. 131, no. 10, pp. 744-751, 2005.

[9] G. Morosiuk, M. J. Riley, and J. B. Odoki, "HDM-4 Modelling Road Deterioration and Works Effects," The Highway Development and Management Series, TRL, Wokingham,UK, 2004.

[10] X. Zhang and H. Gao, "A markov-based road maintenance optimization model considering user costs," Computer-Aided Civil and Infrastructure Engineering, vol. 28, pp. 451-464, 2013.

[11] Q. Dong and B. Huang, "Evaluation of effectiveness and costeffectiveness of asphalt pavement rehabilitations utilizing LTPP data," Journal of Transportation Engineering, vol. 138, no. 6, pp. 681-689, 2012.

[12] A. Mahmoudzadeh, A. Golroo, M. Jahanshahi, and S. Firoozi Yeganeh, "Estimating pavement roughness by fusing color and depth data obtained from an inexpensive RGB-D sensor," Sensors, vol. 19, no. 7, p. 1655, 2019.

[13] B. Al-Omari and M. I. Darter, "Effect of Pavement Deterioration Types on IRI and Rehabilitation," Transportation Research Record 1505, pp. 57-65, TRB, National Research Council, Washington, DC, USA, 1995.

[14] A. E. Sharaf and M. M. Fathy, "An analysis of the impact of different priority setting techniques on network pavement condition," in Proceedings of the Fourth international conference on managing pavements, Durban, South Africa, May 1998.

[15] K. Hall and C. Muñoz, "Estimation of present serviceability index from international roughness index," Transportation Research Record: Journal of the Transportation Research Board, vol. 1655, no. 1, pp. 93-99, 1999.

[16] J. A. Mactutis, S. H. Alavi, and W. C. Ott, "Investigation of relationship between roughness and pavement surface distress 
based on WesTrack Project," Transportation Research Record: Journal of the Transportation Research Board, vol. 1699, no. 1, pp. 107-113, 2000.

[17] S. A. Dewan and R. E. Smith, "Estimating iri from pavement distresses to calculate vehicle operating costs for the cities and counties of san francisco bay area," Transportation Research Record, vol. 1816, pp. 65-72, 2002.

[18] K. Park, N. E. Thomas, and K. Wayne Lee, "Applicability of the international roughness index as a predictor of asphalt pavement condition," Journal of Transportation Engineering, vol. 133, no. 12, pp. 706-709, 2007.

[19] A. K. Sandra and A. K. Sarkar, "Development of a model for estimating International Roughness Index from pavement distresses," International Journal of Pavement Engineering, vol. 14, no. 8, pp. 715-724, 2013.

[20] J. R. Prasad, S. Kanuganti, P. J. Bhanegaonkar, A. K. Sarkar, and A. Shriniwas, "Development of relationship between roughness (IRI) and visible surface distresses: a study on PMGSY roads," in Proceedings of the 2nd Conference of Transportation Research Group of India (2nd CTRG), Transportation Research Group of India, Agra, India, September 2013.

[21] S. Arhin and E. C. Noel, "Predicting pavement condition index using international roughness index in Washington DC, USA," Report DDOT-RDT-14-03, pp. 1-54, Howard University Transportation Research Center, Washington, DC, USA, 2014.

[22] J. D. Lin, J. T. Yau, and L. H. Hsiao, Correlation Analysis between International Roughness Index (IRI) and Pavement, Transportation Research Board, Washington, DC, USA, 2003.

[23] H. Shahnazari, M. A. Tutunchian, M. Mashayekhi, and A. A. Amini, "Application of soft computing for prediction of pavement condition index," Journal of Transportation Engineering, vol. 138, no. 12, pp. 1495-1506, 2012.

[24] M. Arabani, S. Sasanian, Y. Farmand, and M. Pirouz, "Roughset theory in solving road pavement management problems (case study: ahwaz-Shush Highway)," Computational Research Progress in Applied Science and Engineering, vol. 3, no. 2, pp. 62-70, 2017.

[25] A. A. Elhadidy, S. M. El-Badawy, and E. E. Elbeltagi, "A simplified pavement condition index regression model for pavement evaluation," International Journal of Pavement Engineering, vol. 22, no. 5, pp. 643-652, 2021.

[26] S. M. Piryonesi and T. E. El-Diraby, "Examining the relationship between two road performance indicators: pavement condition index and international roughness index," Transportation Geotechnics, vol. 26, Article ID 100441, 2021.

[27] M. Z. Bashar and C. Torres-Machi, "Performance of machine learning algorithms in predicting the pavement international roughness index," Transportation Research Record: Journal of the Transportation Research Board, vol. 2675, Article ID $0361198120986171,2021$.

[28] ASTM D6433-03, Standard Practice for Roads and Parking Lots Pavement Condition Index Surveys, ASTM international, West Conshohocken, PA, USA, 2004.

[29] ASTM E950-98, Standard Test Method for Measuring the Longitudinal Profile of Traveled Surfaces with an Accelerometer Established Inertial Profiling Reference, ASTM international, West Conshohocken, PA, USA, 2003.

[30] M. J. Samet, "Development of accident modification factors in two-lane highways," Computational Research Progress in Applied Science and Engineering, vol. 2, no. 4, 2016.

[31] A. Ghasemzadeh Mahani, P. Bazoobandi, S. M. Hosseinian, and H. Ziari, "Experimental investigation and multi-objective optimization of fracture properties of asphalt mixtures containing nano-calcium carbonate," Construction and Building Materials, vol. 285, Article ID 122876, 2021.

[32] H. Ziari, H. Divandari, S. M. Seyed Ali Akbar, and S. M. Hosseinian, "Investigation of the effect of crumb rubber powder and warm additives on moisture resistance of SMA mixtures," Advances in Civil Engineering, vol. 2021, Article ID 6653594, 12 pages, 2021.

[33] M. Mazari and D. D. Rodriguez, "Prediction of pavement roughness using a hybrid gene expression programmingneural network technique," Journal of Traffic and Transportation Engineering, vol. 3, no. 5, pp. 448-455, 2016. 